\title{
Vertical Product Differentiation, Entry-Deterrence Strategies, and Entry Qualities
}

\author{
Yong-Hwan Noh and GianCarlo Moschini \\ Working Paper 05-WP 403 \\ May 2006 (Revised)
Center for Agricultural and Rural Development
lowa State University
Ames, lowa 50011-1070
www.card.iastate.edu

Yong-Hwan Noh is an economist with the Bank of Korea (Seoul, Republic of Korea) and GianCarlo Moschini is a professor of economics at lowa State University (Ames, lowa, USA).

This publication is available online on the CARD Web site: www.card.iastate.edu. Permission is granted to cite this information with appropriate attribution to the authors.

Questions or comments about the contents of this paper should be directed to Yong-Hwan Noh, Institute for Monetary and Economic Research, Bank of Korea, Seoul 100-794, Republic of Korea; Ph: +82-2-759-5416; E-mail: yonghwan.noh@gmail.com.

lowa State University does not discriminate on the basis of race, color, age, religion, national origin, sexual orientation, gender identity, sex, marital status, disability, or status as a U.S. veteran. Inquiries can be directed to the Director of Equal Opportunity and Diversity, 3680 Beardshear Hall, (515) 294-7612. 


\begin{abstract}
We analyze the potential entry of a new product into a vertically differentiated market. Here the entry-deterrence strategies of the incumbent firm rely on "limit qualities." The model assumes quality-dependent marginal production costs and considers sequential quality choices by an incumbent and an entrant. Entry-quality decisions and the entry-deterrence strategies are related to the fixed cost necessary for entry and to the degree of consumers' taste for quality. We detail the conditions under which the incumbent increases its quality level to deter entry. Quality-dependent marginal production costs in the model entail the possibility of inferior-quality entry as well. Welfare is not necessarily improved when entry is encouraged rather than deterred.
\end{abstract}

Keywords: entry deterrence, quality choice, vertical product differentiation.

JEL classification: C72; D43; L11 


\section{Introduction}

The use of entry deterrence strategies by market incumbents has long been a topic of interest in industrial organization, following the pioneering work of Bain (1956, chapter 4) and Dixit (1979). Many models in this setting emphasize the use of "limit pricing" or "limit quantities" as the established firm's strategic tool for deterring entry. But clearly, as recognized by Schmalensee (1978) among others, firms can compete in non-price aspects such as product differentiation. Indeed, quality choices are of paramount importance in industries where innovation is critical, such as in the hightechnology sector. Quality choices are often studied within the "vertical product differentiation" (VPD) model, where product variants differ in their quality and consumers differ in their willingness to pay for quality, following the pioneering work of Mussa and Rosen (1978), Gabszewicz and Thisse (1979), and Shaked and Sutton $(1982,1983)$. The study of entry deterrence in this setting leads to the notion of "limit quality," the minimum quality of the incumbent that deters entry, which is used by Donnenfeld and Weber (1995).

This paper provides a specific study of entry deterrence in a VPD context. A distinctive feature of our model is the assumption of quality-dependent marginal production costs. In addition we address the issue of market coverage as an endogenous feature of the market, which we relate to the degree of consumers' taste for quality. Our work builds on an established literature. Particularly relevant are the contributions of Hung and Schmitt $(1988,1992)$ and Donnenfeld and Weber $(1992$, 1995), who used a type of Shaked and Sutton (1982) VPD model where goods can be directly ranked by qualities to examine how the incumbent's choice of product quality depends on the size of the entrant's setup costs. The original VPD model of Shaked and Sutton (1982) showed that quality differences relax price competition: one firm selects the maximum product quality and the other chooses the minimum quality to lessen price competition in the production stage of the game, in the absence of an entry threat. Although entry deterrence can only be temporary, Hung and Schmitt (1988, 1992) altered this framework by considering sequential entry and subsequent threat of entry. Thus, they showed that the threat of entry induces the incumbent firm (or the first mover) to provide a lower 
product quality than the technological maximum quality. Also, with the threat of entry, Hung and Schmitt showed that quality differentiation in duopoly equilibrium is reduced.

Donnenfeld and Weber (1995) investigated how product competition among duopoly incumbents and a potential entrant's fixed entry cost affect the entry-deterrence strategies and product qualities. A similar analysis, in which both variable and fixed costs for improving qualities are zero, was presented in Donnenfeld and Weber (1992). Their results show that rivalry among incumbents associated with simultaneous quality choice results in excessive entry deterrence, while the incumbents are likely to accommodate entry if they collude. In particular, they confirmed a finding of Shaked and Sutton (1982) under the assumption of sufficiently high fixed entry costs, in that entry is blockaded and incumbents choose maximally differentiated product qualities to reduce price competition.

The results from the foregoing VPD models are limited to the case of quality-independent production marginal costs. Thus, this setup cannot reflect the fact that the higher-quality good may be more expensive to manufacture (because of, for instance, requirements of more skilled labor or more expensive raw materials and inputs). This observation is important because, with quality-dependent production cost, the standard VPD "high-quality advantage" result (in which the firm choosing to produce the high-quality good earns higher profits in equilibrium than does the low-quality firm) need not hold. ${ }^{1}$ The fact that entry deterrence in a VPD context is sensitive to the specification of cost was investigated by Lutz (1997). By assuming that a portion of the fixed costs depends on the quality chosen by the firm, he explains how the entry-deterrence behavior of the incumbent depends on a combination of fixed costs and market size. But because in Lutz (1997) the unit production cost (normalized to zero) does not depend on quality, the results obtained are still not free from the highquality advantage property.

\footnotetext{
${ }^{1}$ Choi and Shin (1992), Tirole (1988), Aoki and Prusa (1996), and Lehmann-Grube (1997) impose the high-quality advantage by assuming a quality-independent production cost structure, while Lambertini (1996) and Wang (2003) note that the high-quality advantage with sequential or simultaneous quality choice does not necessarily hold with a quality-dependent production cost.
} 
The present study considers entry-deterrence in a VPD three-stage game with one incumbent and one potential entrant. First, the incumbent decides its product quality. Next, the potential entrant, having observed the action taken by the incumbent, decides whether to enter or not and what quality to produce in the case of entry. In the last stage of the game, both firms compete on a price level (if there is entry). Our model differs from existing related analyses (e.g., Hung and Schmitt 1988 and 1992; Donnenfeld and Weber 1992 and 1995) mostly because we specify a quality-dependent marginal production cost, such that a higher quality is associated with a higher variable cost. In such a setting, no particular variety guarantees higher profits, and although firms want to differentiate products to soften price competition, they do not differentiate them completely but determine them in the interior of the feasible quality interval. ${ }^{2}$ As in Donnenfeld and Weber (1995), we also maintain that the incumbent does not incur any entry cost, while the potential entrant must incur a fixed cost in order to enter. Entry occurs whenever strictly positive profits can be earned but can be deterred by the quality choice of the incumbent (which acts as a Stackelberg leader in determining its product quality).

The entry-deterrence equilibrium outcomes that we characterize are in the spirit of the pioneering idea of Bain (1956), as used in many studies (e.g., Dixit 1979; Tirole 1988, chapter 8; Donnenfeld and Weber 1995). Specifically, if the fixed entry cost is large enough, we find the case of "blockaded entry," whereby the incumbent monopolist does not modify its behavior and still can prevent entry. If entry is not blockaded, the incumbent has to compare the benefit of entry prevention against its cost and may either deter or accommodate entry. In the case of "deterred entry," the incumbent modifies its behavior by increasing or decreasing quality in order to deter entry; ${ }^{3}$ otherwise, we have the case of "accommodated entry." Throughout, we emphasize the role that the degree of

\footnotetext{
${ }^{2}$ Maximal product differentiation holds under the covered-market and quality-independent marginal production cost (e.g., Tirole 1988 and Shaked and Sutton 1982).

${ }^{3}$ Thus, in our model we do not consider other strategies that the incumbent may have to deter entry. One such possibility, for example, would be for the incumbent to fill in the product space by offering more than one quality (e.g., Schmalensee 1978). Such an extension would require addressing some subtle strategic considerations (Judd 1985; Siebert 2003) that would considerably change the current focus of the model.
} 
consumers' taste for quality plays in determining these outcomes, and we relate that to the notion of market coverage (which is typically taken as exogenously given in existing studies). We also explore the welfare implications of entry. In particular, we ask whether entry is socially desirable and whether or not entry deterrence is disadvantageous to consumers, and we evaluate market equilibrium values relative to socially optimal levels.

\section{The Model}

The analysis focuses on the entry of an innovative firm into a monopoly market. Consumers are vertically differentiated according to product qualities. Initially, there is a single established firm in an industry, the incumbent (labeled I), that serves the entire market. A single potential entrant (labeled E) enters the market if entry results in a positive payoff and stays out otherwise. We capture the incumbent's advantage by postulating that, whereas the entrant incurs a fixed entry cost to enter the differentiated product market, the incumbent can change its product quality without incurring this fixed cost. Assuming that the entrant needs entry costs for collecting target-market information, advertising a new product, and investing in new transportation channels, we postulate that this entry cost is invariant with respect to eventual quality levels.

The sequence of moves has three periods. In period 1, the incumbent selects its product quality $X_{I}$. In period 2, after observing $X_{I}$, the potential entrant decides whether to enter the market or not, and if entering chooses product quality $X_{E}$. Because entry incurs a fixed cost, a potential entrant decides to enter only if profits exceed the entry cost. If an entrant entered the market with the same quality as the existing variety, undifferentiated Bertrand competition would eliminate all profits; therefore, only differentiated entry, with $X_{E} \neq X_{I}$, can be attained in equilibrium. In the last period (i.e., in the post-entry market), firms compete in prices (if there is entry) given qualities. If the entrant stays out of the market, the incumbent behaves as a monopoly. In the case of entry, the equilibrium concept that we employ is subgame perfection with Bertrand competition in the third stage. 


\section{COST AND DEMAND STRUCTURE}

We modify the monopolist's quality-choice model proposed by Mussa and Rosen (1978) into the duopoly model associated with an entry game. First of all, in the second period of the game, we suppose that the quality follower (a potential entrant) is free to choose any quality level by incurring a sunk and deterministic entry cost $F>0 .{ }^{4}$ That is, the entry cost is invariant with respect to eventual quality levels. As noted earlier, the quality leader (the incumbent) has a cost advantage relative to the entrant (the quality follower) in that it does not need to incur any fixed cost to determine its product quality.

Upon entrance of the new firm, the resulting duopoly supplies vertically differentiated varieties with one-dimensional qualities $X_{i} \in(0, \infty), i=1,2$, with larger values of $X_{i}$ corresponding to higher quality ( $X_{2}>X_{1}>0$ ). To avoid the uninteresting equilibrium in which only the highest possible quality yet cheapest product is produced, we postulate a quality-dependent marginal production cost, such that the higher-quality good is more expensive to manufacture. Specifically, we assume that, for either firm, the cost of producing $Q_{i}$ units of quality $X_{i}$ is

$$
C\left(X_{i}, Q_{i}\right)=X_{i}^{2} Q_{i},
$$

where $Q_{i}$ is the quantity produced by a firm $i$. Note that these variable costs are strictly convex in quality, such that $C^{\prime}\left(X_{i}\right)>0$ and $C^{\prime \prime}\left(X_{i}\right)>0$ hold, but for given quality we have a constant unit production cost. This VPD specification, in which firms compete in prices and incur variable costs of quality, is compatible with that of some earlier models. ${ }^{5}$ In our model, when fixed costs are either absent or quality-independent, convexity in quality of the variable cost function ensures interior solutions in the quality-choosing stage of the game.

\footnotetext{
${ }^{4}$ Of course, with free entry $(F=0)$, the game degenerates into a pure Stackelberg model.

${ }^{5}$ With two-stage quality-price or quality-quantity VPD models, Bonanno and Haworth (1998) introduced a quality-dependent linear form of marginal cost; Mussa and Rosen (1978) and Part III of Motta (1993) used quality-dependent quadratic forms of marginal cost. Thus, in this case, the qualitydependent marginal cost enters directly into the competitor's pricing strategy. Importantly, although they did not explicitly indicate it, the "high-quality advantage" does not necessarily hold in that case.
} 
On the demand side of the market, a continuum of potential consumers is differentiated by the non-negative, one-dimensional taste parameter $\theta$. The parameter $\theta$ is assumed to be distributed uniformly over an interval $[\underline{\theta}, \bar{\theta}]$, with $\bar{\theta}>\underline{\theta}>0$. When entry takes place, we have a situation with two goods differentiated by a quality index $X_{i} \in(0, \infty), i=1,2$. As in Mussa and Rosen (1978), we write the indirect utility function of a consumer $\theta$ patronizing good $i$ as

$$
V_{i}=\theta X_{i}-P_{i}
$$

where $P_{i}$ and $X_{i}$ for $i=\{1,2\}$ are, respectively, the price and quality variables. Thus, consumers agree on the ranking of the two goods but differ in their taste parameter $\theta$. With the assumed uniform distribution of types, the parameters $\underline{\theta}$ and $\bar{\theta}$ relate to both the consumers' average taste for quality and to the consumers' heterogeneity with respect to this attribute. Specifically, for a given $\underline{\theta}$ the length of the support $(\bar{\theta}-\underline{\theta})$ can be interpreted as a measure of consumers' heterogeneity. In what follows we normalize the support of the distribution to the unit length, so that $\bar{\theta}=\underline{\theta}+1$. Hence, in our setting the remaining preference parameter $\underline{\theta}$ will be interpreted as an index of the consumers' taste for quality (i.e., the intensity of their willingness to pay for quality).

In this setting the consumer buys the good that provides highest surplus, or buys nothing if $V_{i}<0$ for both goods. As in related VPD models, an important distinction concerns whether the market, in equilibrium, is "covered" (all consumers purchase a unit of the good) or "uncovered." Here there are four possible market configurations: monopoly with covered market, monopoly with uncovered market, duopoly with covered market, and duopoly with uncovered market. As explained in more detail in what follows, we confine our attention to the preference space where the last outcome (duopoly with uncovered market) is ruled out. For given prices $\left(P_{1}, P_{2}\right)$ and qualities $\left(X_{1}, X_{2}\right)$, the duopoly covered market demand system is

$$
\begin{aligned}
& Q_{1}=\max \left\{0, \min \left\{\bar{\theta}, \theta_{12}\right\}-\underline{\theta}\right\} \\
& Q_{2}=\max \left\{0, \bar{\theta}-\max \left\{\theta_{12}, \underline{\theta}\right\}\right\}
\end{aligned}
$$

where $\theta_{12}=\left(P_{2}-P_{1}\right) /\left(X_{2}-X_{1}\right)$. Therefore, covered-market equilibrium can be characterized by the 
cases in which only the high-quality good is sold, only the low-quality good is sold, or both types of goods are present in the market. When both goods are present, the aggregate demand functions reflect a net substitution pattern (i.e., the cross-price effect is positive).

\section{PRODUCT MARKET EQUILIBRIUM}

Here we consider the firm's production (price competition) stage, after quality levels have been chosen. If the chosen quality levels are such that entry does not occur, the incumbent is a monopolist. Alternatively, upon entry, we have a duopoly in which firms engage in Bertrand competition.

Monopoly Market Equilibrium. Because quality is given at this stage, whether the monopolist will choose to cover the market depends the consumers' taste for quality (i.e., the parameter $\underline{\theta}$ ). Let $\hat{\theta} \equiv P_{I M} / X_{I M}$ (where the subscript "IM" stands for the "incumbent monopoly") denote the marginal consumer who is indifferent between buying a good and not buying at all. Then the (uncovered) market demand for a monopoly is $Q_{I M}=\underline{\theta}+1-\hat{\theta}$.

Recalling that the unit cost is $X_{I M}^{2}$, the monopolist's profit maximization problem is

$$
\begin{gathered}
\operatorname{Max} \\
P_{I M}
\end{gathered} \pi_{I M}=\left(P_{I M}-X_{I M}^{2}\right)\left(\underline{\theta}+1-\frac{P_{I M}}{X_{I M}}\right) .
$$

The optimality conditions for this maximization problem require $\partial \pi_{I M} / \partial P_{I M} \leq 0$. If we have an interior solution so that $P_{I M}^{*} / X_{I M}>\underline{\theta}$, the market is uncovered. But in the case of a corner solution where $P_{I M}^{*} / X_{I M}=\underline{\theta}$, the market is covered. Thus, for a covered market it is necessary that

$$
\left.\frac{\partial \pi_{I M}}{\partial P_{I M}}\right|_{P_{I M}=\underline{\theta} X_{I M}}=\underline{\theta}+1+X_{I M}-2 \underline{\theta} \leq 0 \quad \Leftrightarrow \quad \underline{\theta} \geq 1+X_{I M} .
$$

In this covered-market case, the monopolist's price is at the level at which the least-value consumer $(\underline{\theta})$ gives up all her surplus to purchase the good (i.e., $\left.P_{I M}^{*}=\underline{\theta} X_{I M}\right)$. Thus, the monopolist's product market equilibrium profit is

$$
\pi_{I M}^{*}=\underline{\theta} X_{I M}-X_{I M}^{2} .
$$

Duopoly Market Equilibrium. In a covered market, the profits of the low-quality firm and of the high-quality firm are, respectively, 


$$
\begin{aligned}
& \pi_{1}=\left(P_{1}-X_{1}^{2}\right)\left(\frac{P_{2}-P_{1}}{X_{2}-X_{1}}-\underline{\theta}\right) \\
& \pi_{2}=\left(P_{2}-X_{2}^{2}\right)\left(\underline{\theta}+1-\frac{P_{2}-P_{1}}{X_{2}-X_{1}}\right) .
\end{aligned}
$$

Firms choose their price for given quality levels. Upon solving the Bertrand competition game, we find the Nash equilibrium prices

$$
\begin{aligned}
& P_{1}^{*}=\frac{1}{3}\left\{\left(2 X_{1}^{2}+X_{2}^{2}\right)+(1-\underline{\theta})\left(X_{2}-X_{1}\right)\right\} \\
& P_{2}^{*}=\frac{1}{3}\left\{\left(X_{1}^{2}+2 X_{2}^{2}\right)+(2+\underline{\theta})\left(X_{2}-X_{1}\right)\right\}
\end{aligned}
$$

with the associated equilibrium profits

$$
\begin{aligned}
& \pi_{1}^{*}=\left(X_{2}-X_{1}\right) \frac{\left\{\left(X_{2}+X_{1}\right)+(1-\underline{\theta})\right\}^{2}}{9} \\
& \pi_{2}^{*}=\left(X_{2}-X_{1}\right) \frac{\left\{-\left(X_{2}+X_{1}\right)+(2+\underline{\theta})\right\}^{2}}{9} .
\end{aligned}
$$

Thus, equation (7) and (8) represent the payoff that firms can look forward to at the earlier (qualitychoosing) stage. ${ }^{6}$

Of course, these solutions only apply when, in equilibrium, the duopoly market is in fact covered. For that outcome it is necessary that

$$
X_{1}+X_{2}-2 \leq \underline{\theta} \leq X_{1}+X_{2}+1 \text {. }
$$

This condition ensures non-negative demands (i.e., $Q_{1}{ }^{*} \geq 0$ and $Q_{2}{ }^{*} \geq 0$ ) at the duopoly product market equilibrium. The firm producing a low-quality good would become a monopoly for a low consumers' taste for quality (i.e., low $\underline{\theta}$, so that $\underline{\theta}<X_{1}+X_{2}-2$ ), whereas the firm producing a high-quality good would become a monopoly when the consumers' taste for quality is high (i.e., high $\underline{\theta}$, so that $\underline{\theta}>X_{1}+X_{2}+1$ ). Thus, the restriction in (9) excludes these two extreme cases. Furthermore, for the market to be covered, it must be the case that the consumer with the lowest marginal willingness to pay for quality $(\theta=\underline{\theta})$ has a non-negative surplus when she buys one unit of

\footnotetext{
${ }^{6}$ Note that $\pi_{1}^{*}$ is the incumbent's payoff and $\pi_{2}^{*}$ is the entrant's payoff when entry occurs with the superior-quality good, whereas the entrant's payoff is $\pi_{1}^{*}$ and the incumbent's payoff is $\pi_{2}^{*}$ if entry occurs with the inferior quality.
} 
the low-quality product, i.e., $\underline{\theta} X_{1}-P_{1}^{*} \geq 0$. This implies

$$
\underline{\theta} \geq \frac{\left(2 X_{1}^{2}+X_{2}^{2}\right)+\left(X_{2}-X_{1}\right)}{2 X_{1}+X_{2}}
$$

\section{Equilibrium Quality Choices}

In this section we solve the quality stage of the game (periods 1 and 2), given the Bertrand-

competition solutions at the production stage.

\section{BEST-RESPONSE FUNCTION OF THE ENTRANT}

Consider first the case of entry with a superior quality. The entrant's reduced-form payoff function from price competition in the production stage of the game is given by equation (8), and the incumbent's payoff is given by equation (7). In period 2, a firm $E$ (the Stackelberg follower) chooses $X_{E}$ to maximize $\left[\pi_{E}^{*}\left(X_{I}, X_{E}\right)-F\right]$ for given $X_{I}$. If firm $E$ enters, its best response in terms of the incumbent's quality is given by $X_{E}=\left(X_{I}+\underline{\theta}+2\right) / 3$. Then the entrant's payoff conditional on choosing high-quality entry is given by

$$
\pi_{E}^{H}\left(X_{I}, F\right) \equiv \pi_{E}^{*}\left(X_{I}, \frac{X_{I}}{3}+\frac{\underline{\theta}+2}{3}\right)-F=\frac{4}{9}\left(\frac{\theta+2-2 X_{I}}{3}\right)^{3}-F
$$

The potential entrant enters the market only if this leads to a strictly positive payoff, ${ }^{7}$ that is, when $X_{I}<\lambda_{H}$, where

$$
\lambda_{H} \equiv 1+\frac{\theta}{2}-\left(\frac{3}{2}\right)^{5 / 3} F^{1 / 3}
$$

Now consider the case of entry with an inferior quality. The entrant's payoff function from price competition in the third stage of the game is given by equation (7), and the incumbent's payoff is given by equation (8). In this case, if firm $E$ enters, its best response in terms of the incumbent's quality is given by $X_{E}=\left(X_{I}+\underline{\theta}-1\right) / 3$. Then the entrant's payoff, conditional on choosing lowquality entry, is

\footnotetext{
${ }^{7}$ Actually, when profits are zero, the prospective entrant's choices are indifferent between entry and no entry. Here we adopt the convention that the entrant enters the market only if it can make a strictly positive profit.
} 


$$
\pi_{E}^{L}\left(X_{I}, F\right) \equiv \pi_{E}^{*}\left(X_{I}, \frac{X_{I}}{3}+\frac{\underline{\theta}-1}{3}\right)-F=\frac{4}{9}\left(\frac{1-\underline{\theta}+2 X_{I}}{3}\right)^{3}-F .
$$

The potential entrant enters the market only if this leads to a positive payoff, and this holds when $X_{I}>\lambda_{L}$, where

$$
\lambda_{L} \equiv \frac{\theta-1}{2}+\left(\frac{3}{2}\right)^{5 / 3} F^{1 / 3}
$$

Based on these two conditional responses, we can characterize the actual best-response function of the prospective entrant $\left(B R_{E}\right)$ on the ranges of fixed costs. Let us define the critical value $\hat{X}_{I} \equiv \underline{\theta} / 2+1 / 4$ such that the following equality is satisfied: $\pi_{E}^{L}\left(\hat{X}_{I}, F\right)=\pi_{E}^{H}\left(\hat{X}_{I}, F\right)$. If $X_{I} \leq \hat{X}_{I}$ then entry with superior quality would dominate entry with inferior quality because $\pi_{E}^{H} \geq \pi_{E}^{L}$. Likewise, with $X_{I} \geq \hat{X}_{I}$ then entry with inferior quality would dominate entry with superior quality because $\pi_{E}^{L} \geq \pi_{E}^{H}$. Now, to define completely the $B R_{E}$, we check the ranges of fixed costs. If $\lambda_{L}<\hat{X}_{I}<\lambda_{H}$ then the entrant's positive-profit conditions (12) and (14) are not binding. This is the case when $F<1 / 18$. Whereas, if $\lambda_{H}<\hat{X}_{I}<\lambda_{L}$, then equations (12) and (14) are binding conditions. This holds for $F>1 / 18$. Note that the distance between $\lambda_{H}$ and $\lambda_{L}$ increases as $F$ increases. For $F=1 / 18$ and $X_{I}=\hat{X}_{I}$, entry does not occur because an entrant cannot make positive payoffs. Therefore, there is a discontinuity in the $B R_{E}$, and we can define it on the ranges of fixed costs as follows:

For $F<\frac{1}{18}, \quad X_{E}=\left\{\begin{array}{l}\frac{X_{I}}{3}+\frac{\underline{\theta}+2}{3}, \text { if } X_{I} \leq \hat{X}_{I} \\ \frac{X_{I}}{3}+\frac{\theta}{3}, \text { if } X_{I} \geq \hat{X}_{I}\end{array}\right.$

For $F>\frac{1}{18}, \quad X_{E}= \begin{cases}\frac{X_{I}}{3}+\frac{\theta}{3}+2 & \text { if } X_{I}<\lambda_{H} \\ \text { no entry } & \text { if } X_{I} \in\left[\lambda_{H}, \lambda_{L}\right] \\ \frac{X_{I}}{3}+\frac{\theta}{3}-1 & \text { if } X_{I}>\lambda_{L}\end{cases}$

For $F=\frac{1}{18}, \quad X_{E}= \begin{cases}\frac{X_{I}}{3}+\frac{\theta}{3}+2 & \text { if } X_{I}<\hat{X}_{I} \\ \text { No entry, } & \text { if } X_{I}=\hat{X}_{I} \\ \frac{X_{I}}{3}+\frac{\theta}{3}-1 & \text { if } X_{I}>\hat{X}_{I}\end{cases}$ 
where $\hat{X}_{I}, \lambda_{H}$, and $\lambda_{L}$ are as defined earlier. The best-response functions of the entrant, for the three cases concerning the level of fixed cost $F$, are illustrated in Figures 1-3.

\section{QUALITY LEADERSHIP AND LIMIT QUALITIES}

Consider now the strategic behavior of the incumbent at its quality-stage of the game. We classify the outcomes of the incumbent's quality as a means of limiting the prospective entrant's choices. Because of discontinuity in the prospective entrant's best-response function, it is the size of the fixed cost and the degree of consumers' taste for quality that determine whether or not an entry-deterrence strategy is preferred.

Parameter Restrictions on Market Outcomes. Prior to proceeding with the analysis, it is important to recall that our analysis is meant to apply only to the range of the parameter $\underline{\theta}$ which ensures that the duopoly_ if it arises due to entry-actually covers the market. Consider first the post-entry duopoly (say, the case of $F<1 / 18$ ). When entry occurs with a superior quality, the $B R_{E}$ is given by $X_{E}=\left(X_{I}+\underline{\theta}+2\right) / 3$. The incumbent's quality choice requires $\partial \pi_{I}^{*}\left(X_{I},\left(X_{I}+\underline{\theta}+2\right) / 3\right) / \partial X_{I}=0$. Accordingly, the Stackelberg solution is given by $X_{I S}^{A E H}=\underline{\theta} / 2+1 / 4, X_{E S}^{A E H}=\underline{\theta} / 2+3 / 4, \pi_{I S}^{A E H}=2 / 9$, and $\pi_{E S}^{A E H}=1 / 18-F$. For this Stackelberg equilibrium to cover the market, these solutions must satisfy constraints (9) and (10). It follows that, when entry occurs with a superior quality, the condition $\underline{\theta} \geq \sqrt{19 / 12}$ must be satisfied.

Next, consider the case of entry with an inferior quality. In this case, $B R_{E}$ is given by $X_{E}=\left(X_{I}+\underline{\theta}-1\right) / 3$. The incumbent's quality choice requires $\partial \pi_{I}^{*}\left(X_{I},\left(X_{I}+\underline{\theta}-1\right) / 3\right) / \partial X_{I}=0$. Accordingly, the Stackelberg solution is given by $X_{I S}^{A E L}=\underline{\theta} / 2+1 / 4, X_{E S}^{A E L}=\underline{\theta} / 2-1 / 4, \pi_{I S}^{A E L}=2 / 9$, and $\pi_{E S}^{A E L}=1 / 18-F$. Again, for this Stackelberg equilibrium, to cover the market these solutions must satisfy constraints (9) and (10). It follows that, when entry occurs with an inferior quality, the condition $\underline{\theta} \geq \sqrt{11 / 12}$ must be satisfied.

Consider now the pure monopoly market equilibrium in which entry does not occur. Here the 
monopolist actually determines whether the market is covered or uncovered. If the market is covered, maximizing the monopolist's production profit as given by (6) yields the monopoly solution under the covered-market configuration: $X_{I M}^{*}=\underline{\theta} / 2$ and $\pi_{I M}^{*}=\underline{\theta}^{2} / 4$. For internal consistency, this solution must then satisfy the monopolist's corner solution condition in (5): $\underline{\theta} \geq 1+X_{I M}^{*} \Leftrightarrow \underline{\theta} \geq 2$. Thus, for $\underline{\theta} \leq 2$ the unconstrained monopoly chooses an uncovered market by maximizing $\pi_{I M}^{*}=\left(P_{I M}-X_{I M}^{2}\right)\left(\underline{\theta}+1-P_{I M} / X_{I M}\right)$ with respect to $P_{I M}$ and $X_{I M}$, yielding optimal solutions $P_{I M}^{*}=2(1+\underline{\theta})^{2} / 9, X_{I M}^{*}=(1+\underline{\theta}) / 3$, and $\pi_{I M}^{*}=((1+\underline{\theta}) / 3)^{3}$.

In conclusion, in what follows we shall assume that $\underline{\theta} \in[\sqrt{19 / 12}, \infty)$. This is the most restrictive of the two duopoly conditions derived, implying that if a duopoly arises because of entry it will cover the market. If entry does not occur and the monopoly is unconstrained (the case of blockaded entry), the foregoing analysis indicates the domains of $\underline{\theta}$ that would result in either a covered or an uncovered monopoly market. But of course, entry may not occur because it is deterred by the incumbent's own actions, to which we now turn.

Case 1: Low Fixed Costs and Accommodated Entry. When the entry cost is sufficiently low such that $F<1 / 18$, entry deterrence is not possible, so the solutions for the entry accommodation are Stackelberg duopoly equilibria. Interestingly, the duopoly firm's Stackelberg payoffs are the same regardless of which of the two possible equilibria applies. Specifically, the entrant is indifferent between entry with an inferior quality and entry with a superior quality. That is, points "b" and "e" in Figure 1 are both Stackelberg equilibria.

Case 2: High Fixed Costs and Blockaded Entry. If $F$ is large enough, the potential entrant cannot make a positive profit even when the incumbent selects its pure monopoly quality level. In this case, we say that entry is "blockaded," in which case the incumbent's choice is unconstrained by the threat of entry. This occurs when the unconstrained monopoly quality choice lies between $\lambda_{H}$ and $\lambda_{L}$ (see Figure 3). For the case of relatively high consumers' taste for quality, that is, $\underline{\theta} \geq 2$, the entry cost needs to be sufficiently large to satisfy the covered monopolist's quality level $X_{I M}^{*}=\underline{\theta} / 2 \geq \lambda_{H}$, 
or equivalently $F \geq(2 / 3)^{5}$. For the range of relatively low consumers' taste for quality in which $\underline{\theta} \in[\sqrt{19 / 12}, 2]$, entry is blockaded if the uncovered monopolist's quality satisfies $X_{I M}^{*}=(1+\underline{\theta}) / 3 \geq \lambda_{H}$, or equivalently $F \geq \hat{F}(\underline{\theta})$, where $\hat{F}(\underline{\theta}) \equiv(2 / 81)^{2}(4+\underline{\theta})^{3}$.

Case 3: Moderate Fixed Costs and Deterred Entry. If $F$ falls below the boundary given by $(2 / 3)^{5}$ for $\underline{\theta} \geq 2$, or by $\hat{F}(\underline{\theta})$ for $\underline{\theta} \in[\sqrt{19 / 12}, 2]$, the fixed cost of entry is insufficient to deter entry when the incumbent produces the pure monopoly quality. Then the incumbent has two choices: it could expand its quality level above the unconstrained profit-maximizing level to deter entry; or it could invite entry by choosing its quality level at a point less than $\lambda_{H}$ or greater than $\lambda_{L}$. To analyze the entry-deterrence strategy of the incumbent, we define $X_{I}^{B} \in\left[\lambda_{H}, \lambda_{L}\right]$ as the quality level that discourages entry, where the superscript B stands for "barrier." Then $X_{I}^{B}$ satisfies $\underset{X_{E}}{\operatorname{Max}_{E}} \pi_{E}^{*}\left(X_{E}, X_{I}^{B}\right)-F=0$

First, consider the case of $F=1 / 18$. If entry were accommodated the incumbent's profit would increase as $X_{I} \rightarrow \hat{X}_{I}$, meaning that the payoff that the incumbent can get from accommodation of entry is bounded above by $\lim _{X_{I} \rightarrow \hat{X}_{I}} \pi_{I}^{*}\left(X_{I}, X_{E}\left(X_{I}\right)\right)=2 / 9$. By choosing $X_{I}=\hat{X}_{I}$, on the other hand, the incumbent deters entry and, if the market is covered, obtains a payoff of $\pi_{I M}^{*}\left(X_{I}^{B}=\hat{X}_{I}\right)=(2 \underline{\theta}-1)(2 \underline{\theta}+1) / 16$. Upon checking the monopolist's covered-market restriction (5), we find that the condition $\underline{\theta} \geq 1+X_{I}^{B} \Leftrightarrow \underline{\theta} \geq 5 / 2$ must be satisfied in order for this constrained monopolist's equilibrium to cover the market. For $\underline{\theta} \in[\sqrt{19 / 12}, 5 / 2)$, therefore, the choice of $X_{I}=\hat{X}_{I}$ deters entry and leads to an uncovered market where the incumbent obtains the payoff $\pi_{I M}^{*}\left(X_{I}^{B}=\hat{X}_{I}\right)=(2 \underline{\theta}+1)(2 \underline{\theta}+3)^{2} / 256$. For either market configuration, it is easily verified that $\pi_{I M}^{*}\left(X_{I}^{B}=\hat{X}_{I}\right)>2 / 9$, and thus, when $F=1 / 18$, entry is deterred by the incumbent.

Second, consider the case in which $F>1 / 18$ but entry is not blockaded, that is, 
$F \leq \min \left\{(2 / 3)^{5}, \hat{F}(\underline{\theta})\right\}$. In this case, entry can be deterred with either a covered or an uncovered market. If the (entry deterred) market is covered, because $\partial \pi_{I M}^{*} / \partial X_{I M}=\underline{\theta}-2 X_{I M}<0$ for all $X_{I}>\underline{\theta} / 2$, the incumbent's choice to deter entry is $X_{I}^{B}=\lambda_{H}$. Note that for this constrained monopoly choice to cover the market, it is necessary that $\underline{\theta} \geq 1+X_{I}^{B} \Leftrightarrow F \geq \tilde{F}(\underline{\theta})$, where $\tilde{F}(\underline{\theta}) \equiv(2-\underline{\theta} / 2)^{3}(2 / 3)^{5}$. On the other hand, if entry were accommodated and occurred with a high quality, the payoff of the incumbent would be bounded above by $\lim _{X_{I} \rightarrow \lambda_{H}} \pi_{I}^{*}\left(X_{I}, X_{E}\left(X_{I}\right)\right)$. It is readily verified that $\underline{\theta} \geq 2$ is a sufficient condition for $\pi_{I M}^{*}\left(X_{I}^{B}=\lambda_{H}\right)>\lim _{X_{I} \rightarrow \lambda_{H}} \pi_{I}^{*}\left(X_{I}, X_{E}\left(X_{I}\right)\right)$. Hence, the incumbent deters entry with a covered market when $\underline{\theta} \geq 2$ and $\tilde{F}(\underline{\theta}) \leq F<(2 / 3)^{5}$. For the remaining portion of the parameter space, entry is still deterred, but the resulting market is an uncovered monopoly. Specifically, this occurs when $\sqrt{19 / 12} \leq \underline{\theta} \leq 2$ and $1 / 18<F<\hat{F}(\underline{\theta})$, or when $2 \leq \underline{\theta} \leq 5 / 2$ and $1 / 18<F<\tilde{F}(\underline{\theta})$. In either case, again, the incumbent's optimal choice is to set $X_{I}^{B}=\lambda_{H}$.

Summary of Incumbent Strategies. The parametric domain that pertains to the various configurations of the incumbent's equilibrium strategies discussed in the foregoing are illustrated in Figure 4. Market equilibrium values for each entry-deterrence regime are readily computed and are summarized in Table 1 . For entry costs such that $F \geq 1 / 18$, "deterred entry" (DE) or "blockaded entry" (BE) ensure that the potential entrant cannot obtain a positive payoff. In this region of the entry cost, the incumbent may modify its quality-choice behavior relative to the pure monopoly solution in order to prevent entry.

Whether to deter or accommodate entry depends on the magnitude of entry costs $F$ and on the consumers' taste parameter $\underline{\theta}$. First, if the entry cost is sufficiently high, there is no entry even when the incumbent plays its pure monopoly quality level. That is, in this case the incumbent firm blockades entry simply by choosing its unconstrained monopolist's quality level. Second, for a certain moderate range of entry costs, the unconstrained monopoly optimum cannot be achieved (the pure 
monopoly equilibrium level of quality is not adequate to deter entry). In this case the incumbent engages in entry deterrence by increasing its product quality to prevent the prospective entrant from entering the market. Third, when the entry cost is sufficiently low, so that $F<1 / 18$, entry is accommodated and the incumbent selects a quality that is strictly higher than the monopolist's choice. Note that when entry is accommodated, the entrant is indifferent between entry with an inferior quality and entry with a superior quality. ${ }^{8}$ The following Proposition 1 , and Figure 4 , characterize the entrant's quality choice and the incumbent's deterrence strategies.

Proposition 1. Fixed entry costs and consumers' taste for quality affect the equilibrium solution as follows: (i) the incumbent accommodates entry if entry cost is below a certain limit $(F<1 / 18)$; (ii) entry is effectively blockaded if the entry cost is large enough, but this cost boundary depends on the nature of the market (i.e., on the degree of consumers' taste for quality); (iii) for an intermediate range of the fixed entry cost the incumbent deters entry by biasing its quality choice upward. Entry deterrence can occur with either a covered or an uncovered market (the former attaining in markets with relatively low appreciation for quality).

\section{Welfare}

In this section we consider the normative aspects of the entry problem that we have studied. First, we investigate how the market equilibrium levels of consumer surplus and social welfare are affected by changes in fixed entry costs. Second, we evaluate the entry-deterrence strategies of the incumbent in terms of social welfare criteria by solving the social planner's maximization problem.

\footnotetext{
${ }^{8}$ Note also that there is a first-mover advantage associated with quality leadership: when entry is accommodated, the incumbent (the Stackelberg leader) obtains larger profits than the entrant (the Stackelberg follower) regardless of the entrant's quality superiority or inferiority (i.e., $\pi_{I}>\pi_{E}$ ). In particular, the first-mover's equilibrium quality is the same regardless of whether the accommodated entry occurs with an inferior or a superior quality (the difference in qualities in either case is $1 / 2$ ).
} 


\section{CONSUMER SURPLUS}

Aggregate consumer surplus ( $C S$ ), defined as the sum of the surplus of consumers who buy the lowquality good and that of those who buy the high-quality good, is

$$
\begin{aligned}
C S & =\int_{\underline{\theta}}^{\theta_{12}}\left(\theta X_{1}-P_{1}\right) d \theta+\int_{\theta_{12}}^{1+\underline{\theta}}\left(\theta X_{2}-P_{2}\right) d \theta \\
& =\frac{\left(P_{2}-P_{1}\right)^{2}}{2\left(X_{2}-X_{1}\right)}+\frac{X_{2}}{2}(1+\underline{\theta})^{2}-\frac{X_{1}}{2} \underline{\theta}^{2}+P_{1} \underline{\theta}-P_{2}(1+\underline{\theta})
\end{aligned}
$$

In the absence of entry, regardless of whether entry is deterred or blockaded, the consumer surplus in the monopolist's uncovered and covered markets cases are, respectively

$$
\begin{aligned}
& C S^{U M}=\int_{\frac{P_{M}}{X_{I M}}}^{1+\underline{\theta}}\left(\theta X_{I M}-P_{I M}\right) d \theta=\frac{(1+\underline{\theta})^{2} X_{I M}}{2}-(1+\underline{\theta}) P_{I M}+\frac{P_{I M}^{2}}{2 X_{I M}} \\
& C S^{C M}=\int_{\underline{\theta}}^{1+\underline{\theta}}\left(\theta X_{I M}-P_{I M}\right) d \theta=\frac{(1+2 \underline{\theta}) X_{I M}}{2}-P_{I M} .
\end{aligned}
$$

Given these definitions, by using the market equilibrium values of quality in Table 1 we can obtain the equilibrium consumer surplus for the various configurations of the two exogenous parameters (the preference parameter $\underline{\theta}$ and the level of fixed cost $F$, as illustrated in Figure 4). These equilibrium consumer surplus values are readily calculated and are reported in Table 2.

Figure 5 depicts how consumer surplus changes as the fixed entry cost changes. ${ }^{9}$ The response has three distinctive phases. First, when the fixed cost is so large that entry is blockaded, the incumbent's quality choice and its price are not dependent on the magnitude of a fixed cost. Thus, the consumer surplus is constant in this region. Second, when the fixed entry cost decreases and so entry is not blockaded, then as $F$ decreases the monopolist deters entry by progressively increasing quality. If the population of consumers has a relatively low taste for quality (i.e., low $\underline{\theta}$, the uncovered monopoly case) then this increase reduces consumer surplus. But if consumers have a high enough taste for quality (as indicated by higher values of $\underline{\theta}$, leading to the covered monopoly case), then the

\footnotetext{
${ }^{9}$ Figure 5-b specifically pertains to the case of $\underline{\theta} \in\left(\underline{\theta}^{*}, 5 / 2\right)$, where $\underline{\theta}^{*} \cong 2.0939$ is the root of $\left(8 \underline{\theta}^{3}+28 \underline{\theta}^{2}+30 \underline{\theta}+9\right) / 512=\underline{\theta} / 4$ that lies in the domain of interest. For $\underline{\theta} \in\left(2, \underline{\theta}^{*}\right)$ the point $\left(8 \underline{\theta}^{3}+28 \underline{\theta}^{2}+30 \underline{\theta}+9\right) / 512$ in Figure 5-b is below $\underline{\theta} / 4$.
} 
monopolist's actions can increase consumer surplus. Third, when the fixed cost is so small that the incumbent cannot deter entry, product qualities and prices and hence consumer surplus are independent of the level of fixed cost because the entrant's positive-profit conditions, which depend on $F$, are not binding. In particular, the consumer surplus from the accommodated entry is higher than that of the deterred entry and blockaded entry. That is, consumers benefit from more variety. The following proposition summarizes how consumer surplus varies across fixed costs.

Proposition 2. (i) The consumer surplus for markets with relatively high consumers' willingness to pay for quality $(\underline{\theta} \geq 5 / 2)$ is non-increasing in fixed costs. That is, both actual entry and the potential entry associated with deterred entry increase consumer surplus relative to the pure monopoly situation. (ii) For cases with relatively low taste for quality, the consumer surplus from accommodated entry is higher than that of blockaded or deterred entry. But whereas an increasing fixed cost makes entry deterrence more likely, consumer surplus is not necessarily monotonic in the fixed cost.

\section{EQUILIBRIUM SOCIAL WELFARE}

Combining measures of consumer surplus along with firm profits, when the potential entrant actually enters the market, social welfare is

$$
\begin{aligned}
W\left(X_{1}, X_{2} ; P_{1}, P_{2}\right) & =\frac{\left(P_{2}-P_{1}\right)^{2}}{2\left(X_{2}-X_{1}\right)}+\frac{X_{2}}{2}(1+\underline{\theta})^{2}-\frac{X_{1}}{2} \underline{\theta}^{2}+P_{1} \underline{\theta}-P_{2}(1+\underline{\theta}) \\
& +\left(P_{1}-X_{1}^{2}\right)\left(\frac{P_{2}-P_{1}}{X_{2}-X_{1}}-\underline{\theta}\right)+\left(P_{2}-X_{2}^{2}\right)\left(1+\underline{\theta}-\frac{P_{2}-P_{1}}{X_{2}-X_{1}}\right)-F .
\end{aligned}
$$

In the absence of entry, social welfare for the uncovered and covered monopoly cases, respectively, is

$$
\begin{aligned}
& W^{U M}=\frac{(1+\underline{\theta})^{2} X_{I M}}{2}-(1+\underline{\theta}) P_{I M}+\frac{P_{I M}^{2}}{2 X_{I M}}+\left(P_{I M}-X_{I M}^{2}\right)\left(1+\underline{\theta}-\frac{P_{I M}}{X_{I M}}\right) \\
& W^{C M}=\frac{(1+2 \underline{\theta}) X_{I M}}{2}-P_{I M}+\left(P_{I M}-X_{I M}^{2}\right)
\end{aligned}
$$


Given these definitions, by using the market equilibrium values of quality in Table 1 we can obtain the equilibrium welfare measure for the various configurations of the two exogenous parameters $\underline{\theta}$ and $F$ (see Figure 4). These welfare values are readily calculated and are reported in Table 3.

Figure 6 depicts how the market equilibrium level of social welfare changes as the fixed entry cost changes. ${ }^{10}$ First, when the fixed entry cost is so large that entry is blockaded, the incumbent chooses the same quality and price at any level of $F$. Thus, in this case, social welfare is constant as consumers obtain the same utility and the incumbent monopolist gets the same profits regardless of $F$. Second, for the intermediate level of fixed costs, the incumbent increases both its quality and price as $F$ decreases. In this case, social welfare when the consumers' taste for quality is relatively high increases as $F$ decreases, whereas it decreases in the relatively low taste for quality case. Third, the total welfare of accommodated entry depends on the fixed entry cost because the entrant's fixed entry cost is incurred. In this case, the social welfare increases by the same amount as the decrease of the fixed entry cost.

As we can see, maximum welfare is not necessarily associated with the case of accommodated entry. Although it is deterred, potential entry may be welfare enhancing relative to the pure monopoly situation. In particular, for $\underline{\theta} \geq 5 / 2$, we have entry deterrence abruptly increasing welfare as compared with accommodation. This is because the fixed cost of entry is not incurred, and the increased quality associated with entry deterrence yields more profits and consumer surpluses. From this investigation, we derive an implication that the policy lowering entry barrier is not necessarily welfare enhancing. The result that entry may decrease overall welfare is consistent with

${ }^{10}$ To be precise, the shapes of Figures 6-a and 6-b should be qualified somewhat. Specifically, in Figure 6 -a it is possible for the welfare level in the domain $F \in(0,1 / 18)$ to dip below $(1+\underline{\theta})^{3} / 18$ (this happens for high enough $\underline{\theta}$ in the domain $\underline{\theta} \in[\sqrt{19 / 12}, 2]$ ). In Figure 6-b, the shape depicted is specifically for $\underline{\theta} \in\left(2, \underline{\theta}^{* * *}\right)$, where $\underline{\theta}^{* *} \cong 2.3081$ is the root in the domain of interest that solves $\left(24 \underline{\theta}^{3}+84 \underline{\theta}^{2}+90 \underline{\theta}+27\right) / 512=\left(\underline{\theta}^{2}+\underline{\theta}\right) / 4$. For $\underline{\theta} \in\left(\underline{\theta}^{* *}, 5 / 2\right)$ the point $\left(\underline{\theta}^{2}+\underline{\theta}\right) / 4$ is below the point $\left(24 \underline{\theta}^{3}+84 \underline{\theta}^{2}+90 \underline{\theta}+27\right) / 512$. 
the strand of literature on "excessive entry," where it has been found that entry into an imperfectly competitive market in which a potential entrant must incur fixed costs upon entry, creates a bias toward excessive entry (Mankiw and Whinston, 1986; Suzumura and Kiyono, 1987; Cabral, 2004). We can summarize our results at this juncture as follows.

Proposition 3. Entry deterrence is not necessarily welfare decreasing. For the case of relatively high consumers' taste for quality $(\underline{\theta} \geq 5 / 2)$, maximum welfare is attained at $F=1 / 18$, where entry is deterred. For the case of relatively low consumers' taste for quality (lower values of $\underline{\theta}$ ), maximum welfare can be attained at $F=0$, where entry is accommodated.

\section{SOCIAL OPTIMUM}

The welfare impacts of entry deterrence may be best appreciated if we briefly consider the socially optimal level of qualities under marginal cost pricing. For consistency we continue to suppose that a fixed entry cost (of size $F$ ) is required if a new variety is added to the existing variety. Thus, if a new product is added, the planner will choose the two qualities to maximize welfare (the sum of profits and consumer surplus) as

$$
\begin{aligned}
& \underset{X_{1}, X_{2}}{\operatorname{Max}} \quad W=\int_{\underline{\theta}}^{\tilde{\theta}_{12}}\left(\theta X_{1}-X_{1}^{2}\right) d \theta+\int_{\tilde{\theta}_{12}}^{1+\underline{\theta}}\left(\theta X_{2}-X_{2}^{2}\right) d \theta-F \\
& \text { s.t. } \quad \tilde{\theta}_{12}=\frac{\tilde{P}_{2}-\tilde{P}_{1}}{X_{2}-X_{1}}=\frac{X_{2}^{2}-X_{1}^{2}}{X_{2}-X_{1}}=X_{2}+X_{1} .
\end{aligned}
$$

Solving the problem in (20) yields the efficient level of qualities as $\tilde{X}_{1}=\underline{\theta} / 2+1 / 8$ and $\tilde{X}_{2}=\underline{\theta} / 2+3 / 8$. Note that in our parameter ranges on $\underline{\theta}$, the market will be fully covered with these optimal qualities because $\underline{\theta} \geq \tilde{P}_{1} / \tilde{X}_{1}=\tilde{X}_{1}^{2} / \tilde{X}_{1}=\tilde{X}_{1}=\underline{\theta} / 2+1 / 8 \Leftrightarrow \underline{\theta} \geq 1 / 4$. The maximized level of welfare in this case would be $\tilde{W}_{2}=\left(16 \underline{\theta}^{2}+16 \underline{\theta}+5\right) / 64-F$.

On the other hand, if the planner decides not to introduce a new variety in the economy, then the optimal quality is determined by solving 


$$
\underset{X}{\operatorname{Max}} W=\int_{\underline{\theta}}^{1+\underline{\theta}}\left(\theta X-X^{2}\right) d \theta
$$

Straightforward calculation yields $\tilde{X}=\underline{\theta} / 2+1 / 4$. Note that in our parameter ranges on $\underline{\theta}$, the market will be fully covered with $\tilde{X}$ because $\underline{\theta} \geq \tilde{P} / \tilde{X}=\tilde{X}=\underline{\theta} / 2+1 / 4 \Leftrightarrow \underline{\theta} \geq 1 / 2$. The maximized level of welfare in this case would be $\tilde{W}_{1}=\left(16 \underline{\theta}^{2}+16 \underline{\theta}+4\right) / 64$. Hence, the planner accommodates a new variety in the economy if $\tilde{W}_{2}>\tilde{W}_{1}$, i.e., whenever $F<1 / 64$.

Now, let us compare the market equilibrium level of qualities to the socially optimal level of qualities. In the absence of entry, $X_{I M}^{*}=(1+\underline{\theta}) / 3<(\underline{\theta} / 2+1 / 4)=\tilde{X}$ for $\underline{\theta} \in[\sqrt{19 / 12}, 2]$, $X_{I M}^{*}=\underline{\theta} / 2<\underline{\theta} / 2+1 / 4=\tilde{X}$ for $\underline{\theta} \geq 2$, and $X_{I}^{B}=\lambda_{H}<\underline{\theta} / 2+1 / 4=\tilde{X}$. When entry is accommodated, therefore, profit maximization yields a quality difference that is too high; i.e., $\left(\tilde{X}_{2}-\tilde{X}_{1}\right)-\left(X_{2}{ }^{*}-X_{1}{ }^{*}\right)=1 / 4-1 / 2<0$. Then the following proposition summarizes these results. ${ }^{11}$

Proposition 4. (i) The level of entry costs that makes it socially optimal to have a new quality of good in this economy is $F<1 / 64$. Thus, for $F \in[1 / 64,1 / 18)$, there are too many varieties in the economy relative to the social optimum. (ii) For a fixed entry cost with $F<1 / 64$, Stackelberg firms provide excessive product differentiation, compared with what would be socially desirable. (iii) The incumbent monopolist, whether the entry is deterred or blockaded, strictly undersupplies product quality relative to the social optimum.

\section{Conclusion}

We have analyzed the strategic use of entry deterrence of an established firm and the entrant's quality choice in a vertically differentiated product market. In the Stackelberg game that we have developed, the incumbent influences the quality choice of the entrant by choosing its quality level before the

\footnotetext{
${ }^{11}$ We note the result of the blockaded monopolist undersupplying quality can be related to Spence (1975), where a single-product monopolist in general introduces a bias in product selection at a given output level.
} 
entrant does. This allows the incumbent to limit the entrant's entry decision and quality levels. We characterized the levels of the entrant's fixed costs, and the degree of consumers' taste for quality, that induce the incumbent to engage, in equilibrium, in either entry deterrence or entry accommodation. Also, we compared market equilibrium values to the socially optimal ones.

We find that, first, when the entrant's fixed cost is sufficiently low, the incumbent's optimal strategy is to accommodate entry. In such a case the incumbent selects a quality that is higher than the monopolist's unconstrained choice, and in equilibrium the entrant is actually indifferent between entry with an inferior quality and entry with a superior quality. Second, if the entry cost is in a certain moderate range, the incumbent engages in entry deterrence by increasing its product quality before the entrant enters the market. Deterrence can occur with either a covered or an uncovered market. Third, for a sufficiently high fixed entry cost, entry is efficiently blockaded (the incumbent chooses its unconstrained monopoly quality level). Fourth, it is shown that while consumer surplus is higher when the entry is accommodated than in the absence of entry, maximum total welfare is not necessarily associated with accommodated entry. In particular, in markets with a relatively high consumers' taste for quality, the maximum welfare is attained at the fixed cost level where entry would be deterred. Fifth, for a certain level of fixed entry costs, there are too many varieties in the economy relative to the social optimum. We also show that Stackelberg firms associated with accommodated entry excessively differentiate product qualities to reduce price competition. The incumbent monopolist, whether the entry is deterred or blockaded, strictly undersupplies product quality relative to the social optimum.

We again stress that our analysis on how the existence of a potential entrant influences quality relies on a VPD model with the assumption of quality-dependent variable costs. With this quality-cost specification, as mentioned earlier, the "high-quality advantage" does not necessarily hold. But, we have shown that the incumbent's profit is greater than the entrant's profit, regardless of the entrant's quality regime (i.e., there is a first-mover advantage). 


\section{References}

Aoki, Reiko, and Thomas J. Prusa, 1996, Sequential versus simultaneous choice with endogenous quality. International Journal of Industrial Organization, 15: 103-121.

Bain, Joe S., 1956, Barriers to New Competition: Their Character and Consequences in Manufacturing Industries. Cambridge, Mass.: Harvard University Press.

Bonanno, Giacomo, and Barry Haworth, 1998, Intensity of competition and the choice between product and process innovation. International Journal of Industrial Organization, 16: 495510.

Cabral, Luis M. B., 2004, Simultaneous entry and welfare, European Economic Review 48: 943-957.

Choi, Chong Ju, and Hyun Song Shin, 1992, A comment on a model of vertical product differentiation. Journal of Industrial Economics 40, 2: 229-231.

Dixit, Avinash, 1979, A model of duopoly suggesting a theory of entry barriers. Bell Journal of Economics 10: 20-32.

Donnenfeld, Shabtai, and Shlomo Weber, 1992, Vertical product differentiation with entry. International Journal of Industrial Organization 10: 449-472.

Donnenfeld, Shabtai, and Shlomo Weber, 1995, Limit qualities and entry deterrence. Rand Journal of Economics 35: 113-130.

Gabszewicz, J. Jaskold, and J-F. Thisse, 1979, Price competition, quality and income disparities. Journal of Economic Theory 20: 340-359.

Hung, Nguyen M., and Nicolas Schmitt, 1988, Quality competition and threat of entry in duopoly. Economics Letters 27: 287-292.

Hung, Nguyen M., and Nicolas Schmitt, 1992, Vertical product differentiation, threat of entry, and quality changes. In Market Strategy and Structure, J. M. Alec. Gee and George Norman, eds. Harvester Wheatshearf, New York, pp. 289-307.

Judd, Kenneth L., 1985, “Credible Spatial Preemption.” Rand Journal of Economics 16:153-166. 
Lambertini, Luca, 1996, Choosing roles in a duopoly for endogenously differentiated products. Australian Economic Papers 35: 205-224.

Lehmann-Grube, Ulrich, 1997, Strategic choice of quality when quality is costly: The persistence of the high-quality advantage. Rand Journal of Economics 28, 2: 372-384.

Lutz, Stefan, 1997, Vertical product differentiation and entry deterrence. Journal of Economics 65, 1: 79-102.

Mankiw, N. Gregory and Michael D. Whinston, 1986, Free entry and social inefficiency, Rand Journal of Economics 17, 1: 48-58.

Motta, Massimo, 1993, Endogenous quality choice: Price vs. quantity competition. Journal of Industrial Economics 41, 2: 113-131.

Mussa, Michael, and Sherwin Rosen, 1978, Monopoly and product quality. Journal of Economic Theory 18: 301-317.

Schmalensee, Richard, 1978, Entry deterrence in the ready-to-eat breakfast cereal industry. Bell Journal of Economics 9, 2: 305-327.

Shaked, Avner, and John Sutton, 1982, Relaxing price competition through product differentiation. Review of Economic Studies 49, 1: 3-13.

Shaked, Avner, and John Sutton, 1983, Natural oligopolies. Econometrica 51, 5: 1469-1484.

Siebert, Ralph, 2003, Credible Vertical Preemption. CEPR Discussion Paper 4089, July.

Spence, A. Michael, 1975, Monopoly, Quality, and Regulation, Bell Journal of Economics 6, 2: 417429.

Suzumura, Kotaro, Kazuharu Kiyono, 1987, Entry barriers and economic welfare, Review of Economic Studies 54, 1: 157-167.

Tirole, Jean, 1988, The Theory of Industrial Organization. MIT Press, Cambridge, MA.

Wang, X.H., 2003, A Note on the High-quality Advantage in Vertical Differentiation Models, Bulletin of Economic Research 55: 91-99. 
Table 1. Entry-Deterrence Regimes and Equilibrium Outcomes

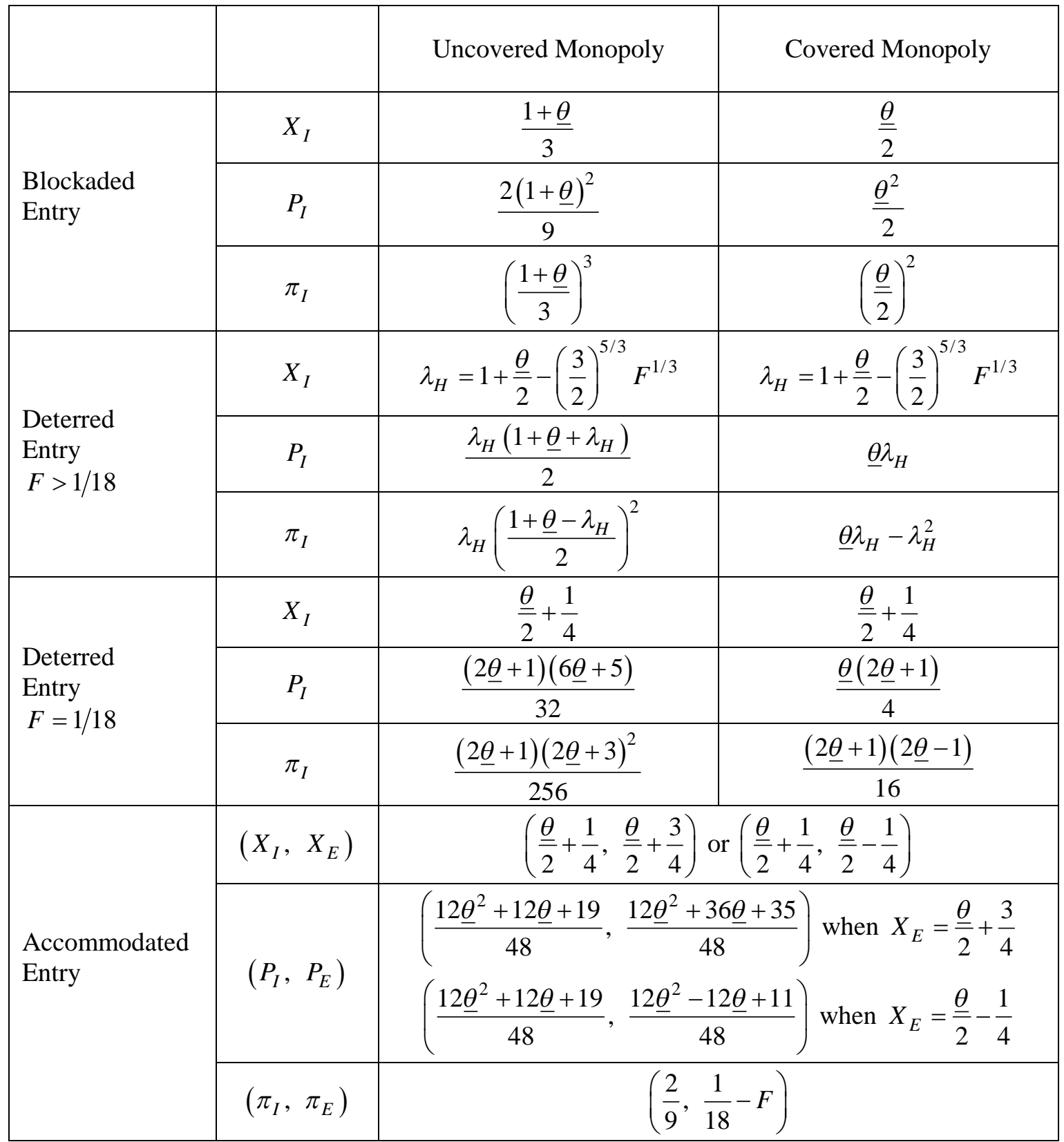

Note: See text and Figure 4 for the parametric domain that pertains to each regime. 
Table 2. Equilibrium Consumer Surplus for each $(F, \underline{\theta})$ domain

\begin{tabular}{|c|c|c|c|}
\hline & $\underline{\theta} \in[\sqrt{19 / 12}, 2]$ & $\underline{\theta} \in[2,5 / 2]$ & $\underline{\theta} \geq 5 / 2$ \\
\hline$F<\frac{1}{18}$ & $\frac{36 \underline{\theta}^{2}+36 \underline{\theta}-35}{144}$ & $\frac{36 \underline{\theta}^{2}+36 \underline{\theta}-35}{144}$ & $\frac{36 \underline{\theta}^{2}+36 \underline{\theta}-35}{144}$ \\
\hline$F=\frac{1}{18}$ & $\frac{8 \underline{\theta}^{3}+28 \underline{\theta}^{2}+30 \underline{\theta}+9}{512}$ & $\frac{8 \underline{\theta}^{3}+28 \underline{\theta}^{2}+30 \underline{\theta}+9}{512}$ & $\frac{2 \underline{\theta}+1}{8}$ \\
\hline$\frac{1}{18}<F<\hat{F}(\underline{\theta})$ & $\frac{\lambda_{H}}{8}\left(\lambda_{H}-(1+\underline{\theta})\right)^{2}$ & - & - \\
\hline$F \geq \hat{F}(\underline{\theta})$ & $\frac{(1+\underline{\theta})^{3}}{54}$ & $-\frac{\lambda_{H}\left(\lambda_{H}-(1+\underline{\theta})\right)^{2}}{8}$ & $\frac{\lambda_{H}}{2}$ \\
\hline$\frac{1}{18}<F<\tilde{F}(\underline{\theta})$ & - & $\frac{\lambda_{H}}{2}$ & $\frac{\lambda_{H}}{2}$ \\
\hline$\tilde{F}(\underline{\theta}) \leq F<(2 / 3)^{5}$ & - & $\underline{\theta}$ & $\underline{\theta}$ \\
\hline$F \geq(2 / 3)^{5}$ & - & & $\frac{\underline{\theta}}{4}$ \\
\hline
\end{tabular}

Note: $\hat{F}(\underline{\theta}), \tilde{F}(\underline{\theta})$ and $\lambda_{H}$ are as defined in the text. 
Table 3. Equilibrium Social Welfare for each $(F, \underline{\theta})$ domain

\begin{tabular}{|c|c|c|c|}
\hline & $\underline{\theta} \in[\sqrt{19 / 12}, 2]$ & $\underline{\theta} \in[2,5 / 2]$ & $\underline{\theta} \geq 5 / 2$ \\
\hline$F<\frac{1}{18}$ & $\frac{36 \underline{\theta}^{2}+36 \underline{\theta}+5}{144}-F$ & $\frac{36 \underline{\theta}^{2}+36 \underline{\theta}+5}{144}-F$ & $\frac{36 \underline{\theta}^{2}+36 \underline{\theta}+5}{144}-F$ \\
\hline$F=\frac{1}{18}$ & $\frac{24 \underline{\theta}^{3}+84 \underline{\theta}^{2}+90 \underline{\theta}+27}{512}$ & $\frac{24 \underline{\theta}^{3}+84 \underline{\theta}^{2}+90 \underline{\theta}+27}{512}$ & $\left(\frac{2 \underline{\theta}+1}{4}\right)^{2}$ \\
\hline$\frac{1}{18}<F<\hat{F}(\underline{\theta})$ & $\frac{3 \lambda_{H}}{8}\left(\lambda_{H}-(1+\underline{\theta})\right)^{2}$ & - & - \\
\hline$F \geq \hat{F}(\underline{\theta})$ & $\frac{(1+\underline{\theta})^{3}}{18}$ & $\frac{3 \lambda_{H}}{8}\left(\lambda_{H}-(1+\underline{\theta})\right)^{2}$ & $\lambda_{H}\left(\frac{1}{2}+\underline{\theta}-\lambda_{H}\right)$ \\
\hline$\frac{1}{18}<F<\tilde{F}(\underline{\theta})$ & - & $\lambda_{H}\left(\frac{1}{2}+\underline{\theta}-\lambda_{H}\right)$ & $\lambda_{H}\left(\frac{1}{2}+\underline{\theta}-\lambda_{H}\right)$ \\
\hline$\tilde{F}(\underline{\theta}) \leq F<(2 / 3)^{5}$ & - & $\underline{\underline{\theta}}+\underline{\theta}$ & $\underline{\underline{\theta}}$ \\
\hline$F \geq(2 / 3)^{5}$ & - & & \\
\hline
\end{tabular}

Note: $\hat{F}(\underline{\theta}), \tilde{F}(\underline{\theta})$ and $\lambda_{H}$ are as defined in the text. 
Figure 1. The Best-Response Function of the Entrant (when $F<1 / 18$ )

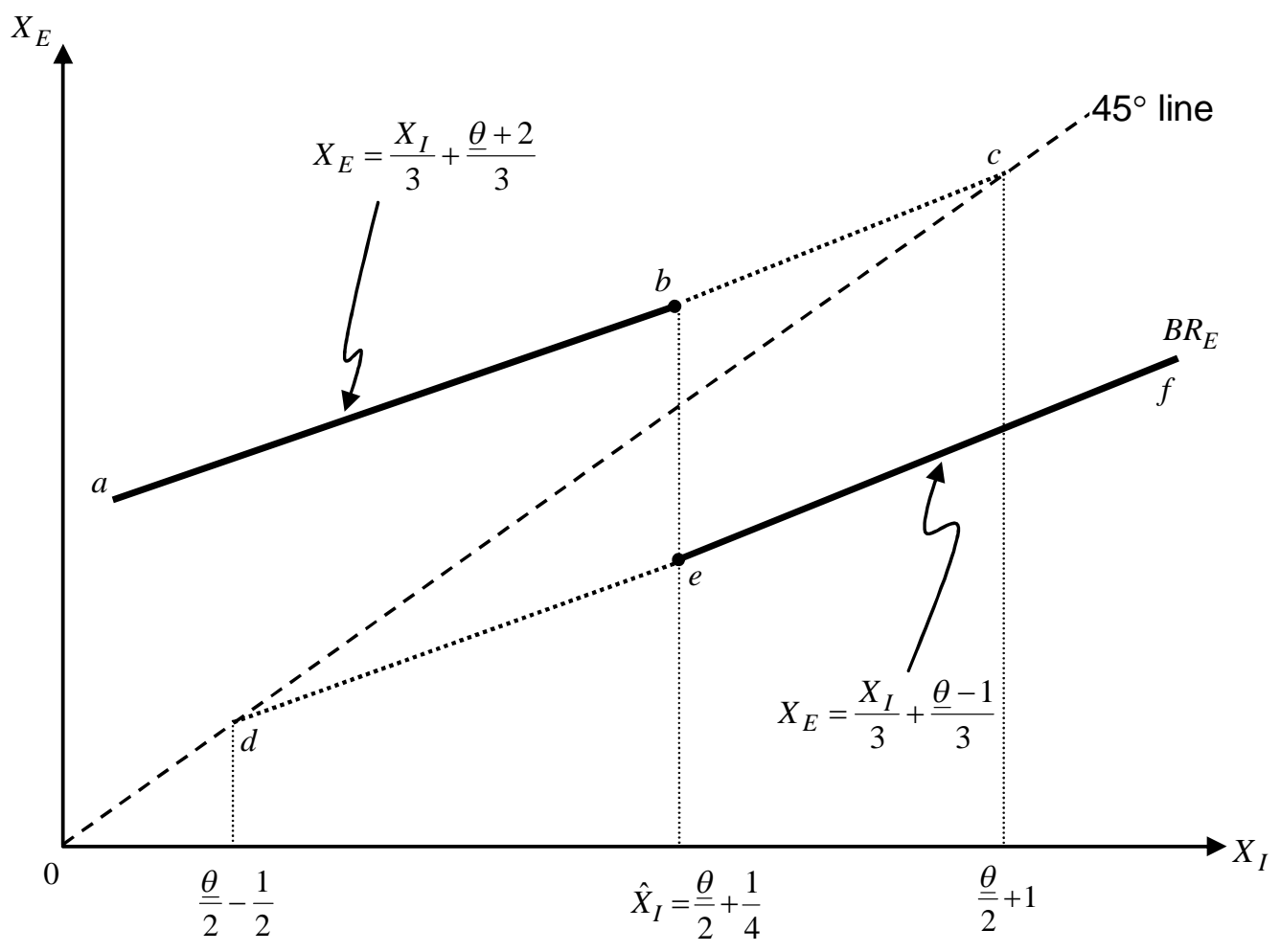

Figure 2. The Best-Response Function of the Entrant (when $F=1 / 18$ )

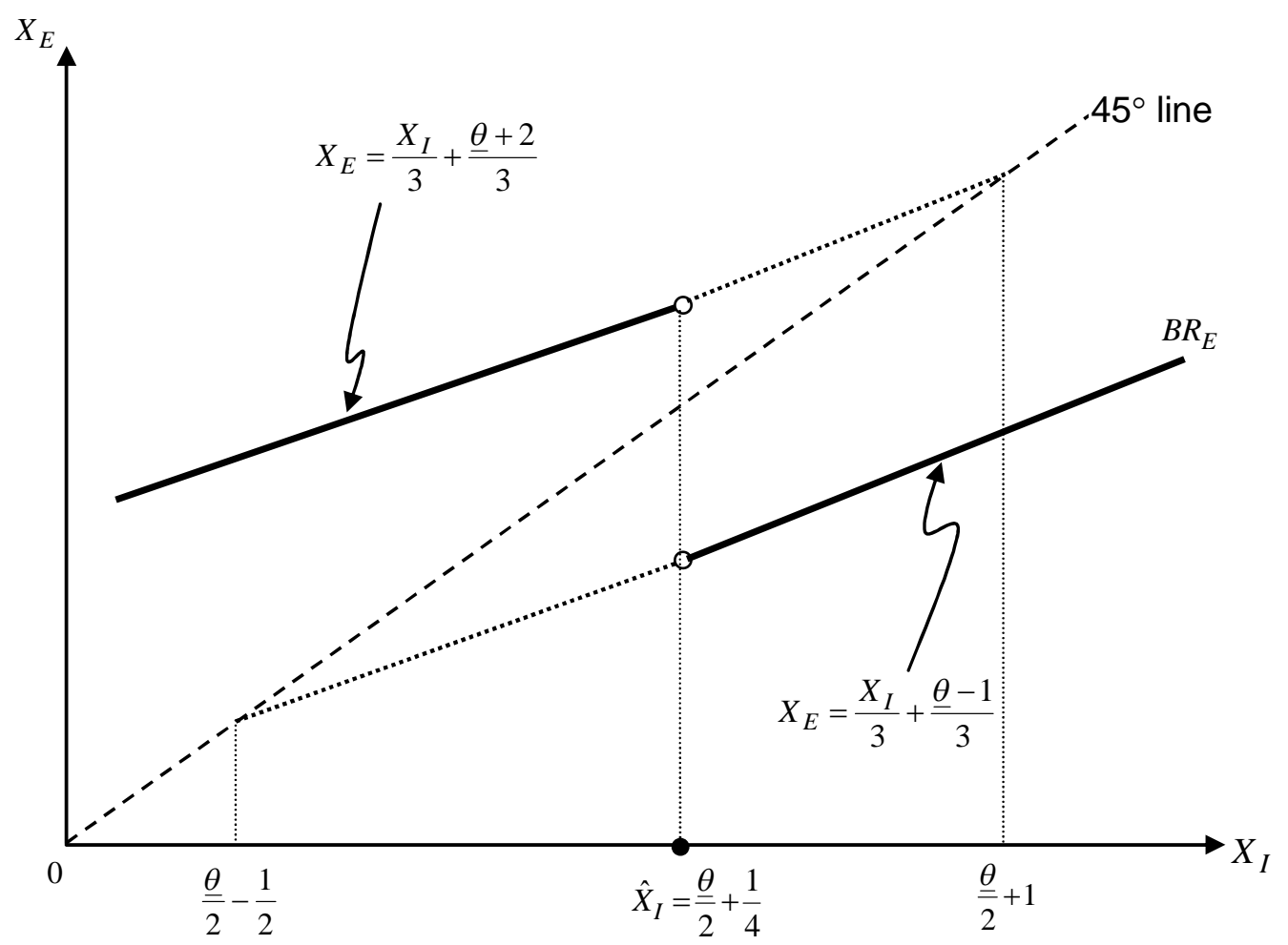


Figure 3. The Best-Response Function of the Entrant (when $F>1 / 18$ )

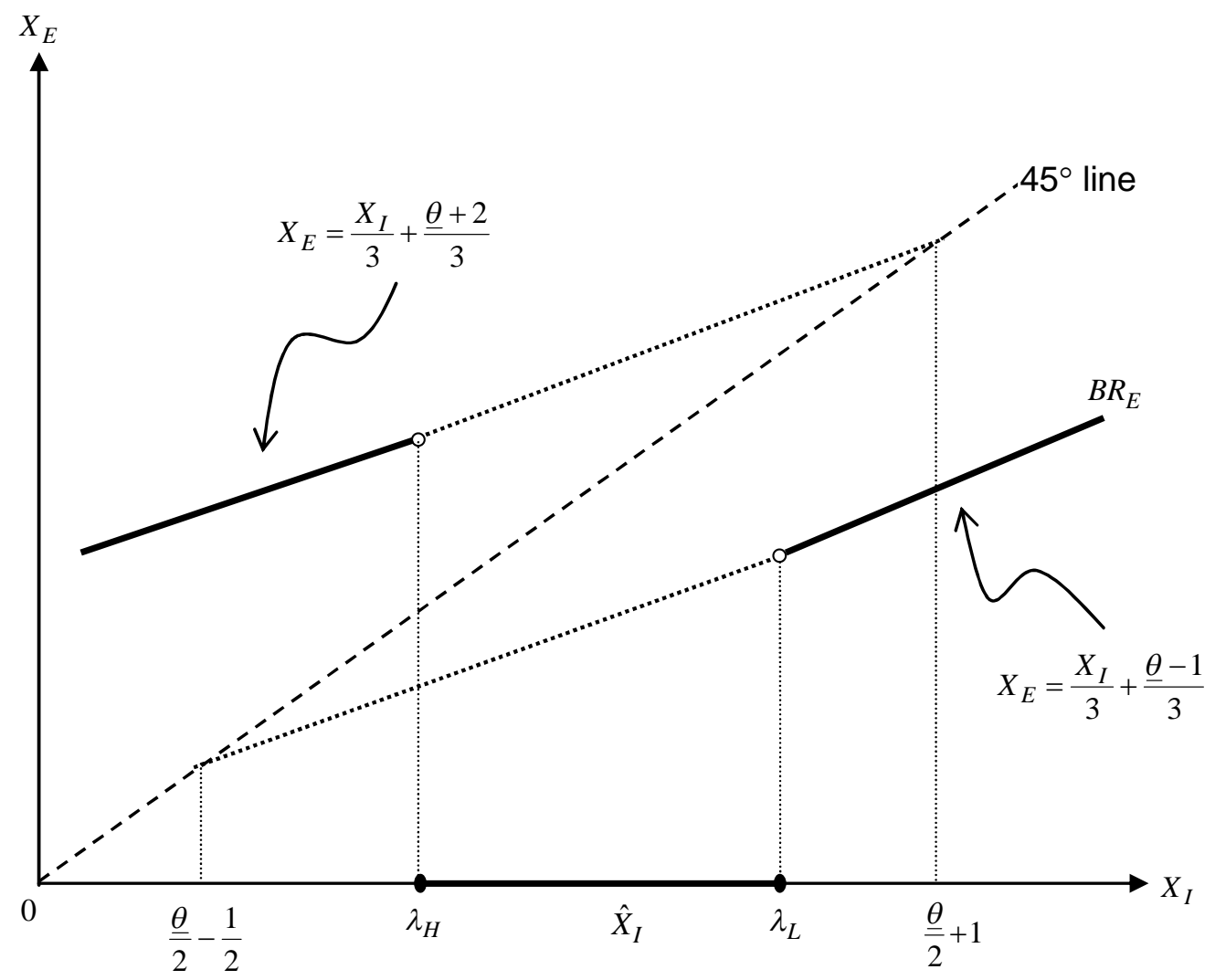

Figure 4. Strategic Entry and Entry-Deterrence Decisions

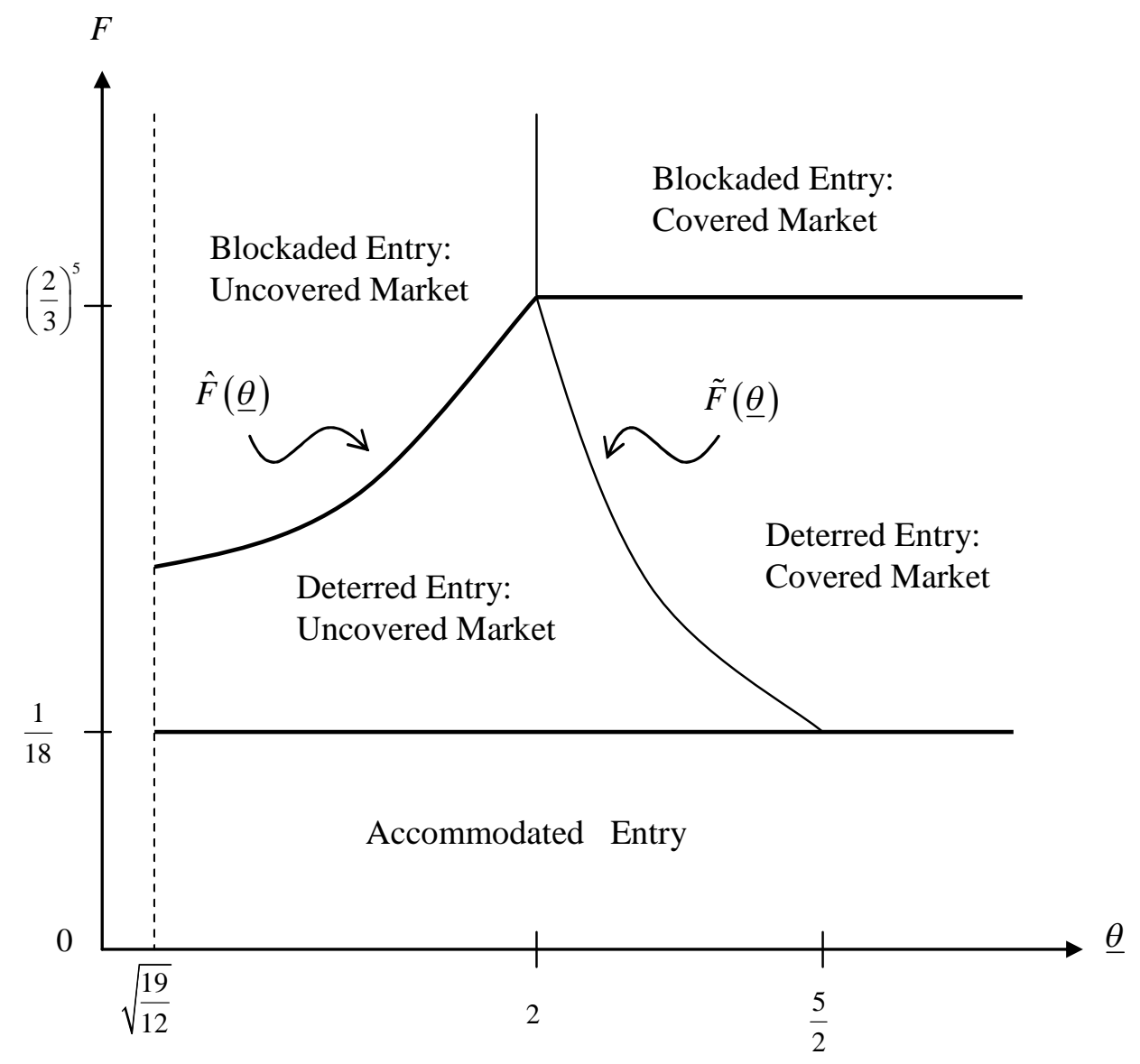


Figure 5-a.

Consumer Surplus:

Case of $\underline{\theta} \in[\sqrt{19 / 12}, 2]$

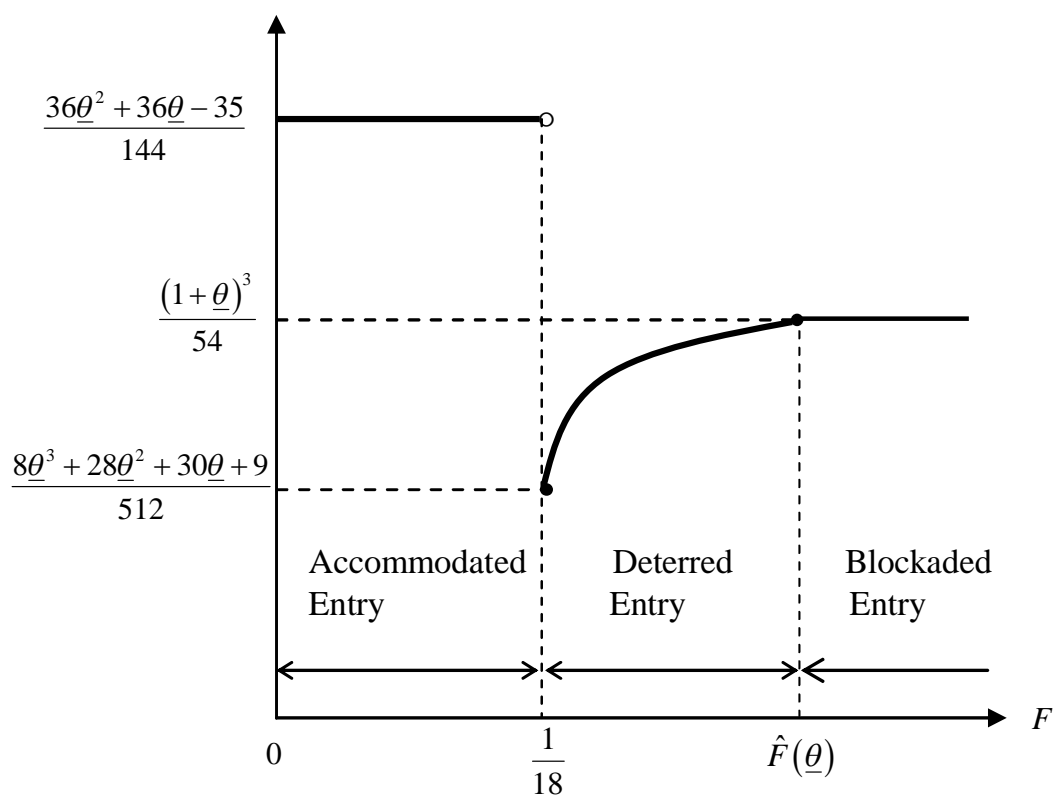

Figure 5-b.

Consumer Surplus:

Case of $\underline{\theta} \in(2,5 / 2)$

Figure 5-c.

Consumer Surplus:

Case of $\underline{\theta} \geq 5 / 2$

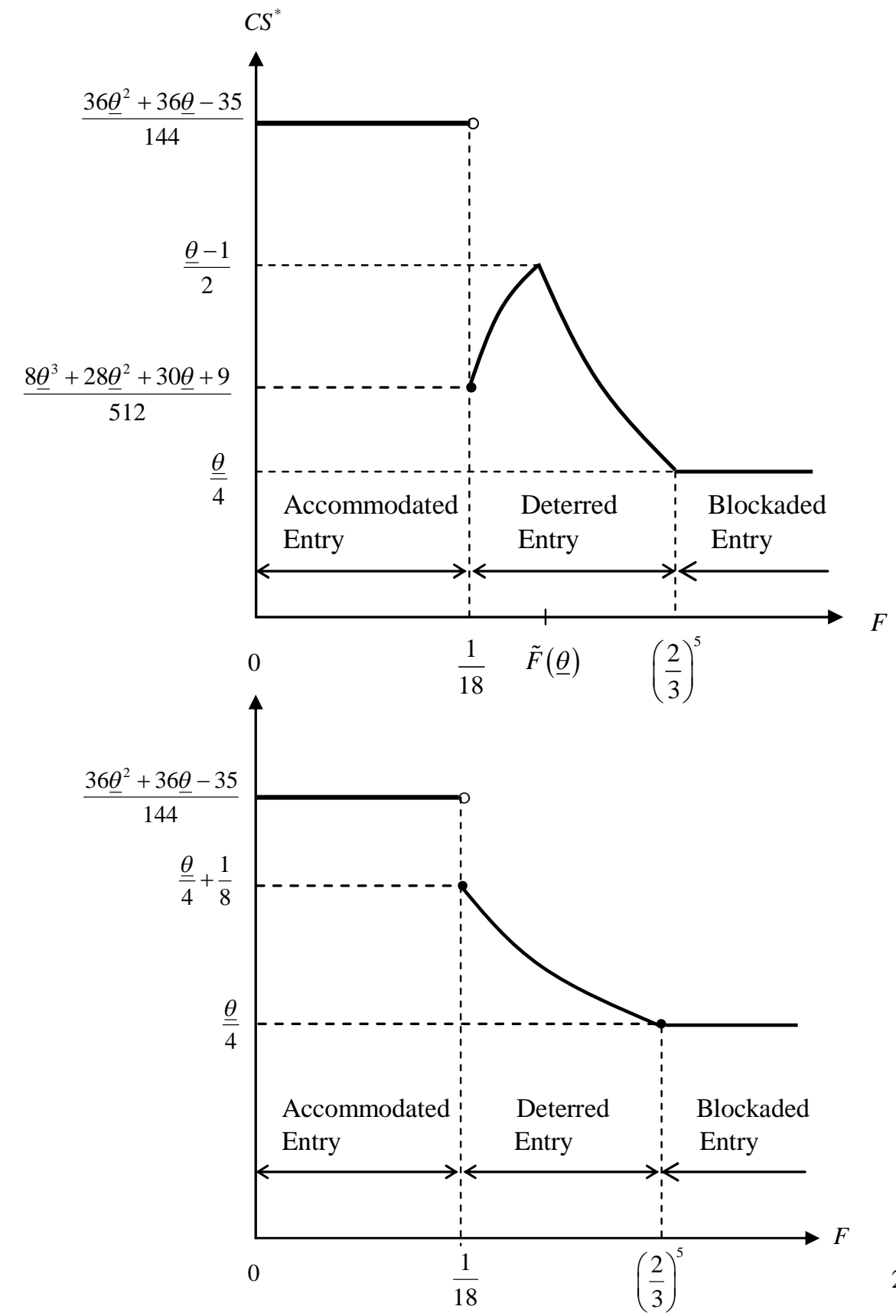


Figure 6-a.

Equilibrium Social Welfare

Case of $\underline{\theta} \in[\sqrt{19 / 12}, 2]$

Figure 6-b.

Equilibrium Social Welfare

Case of $\underline{\theta} \in(2,5 / 2)$
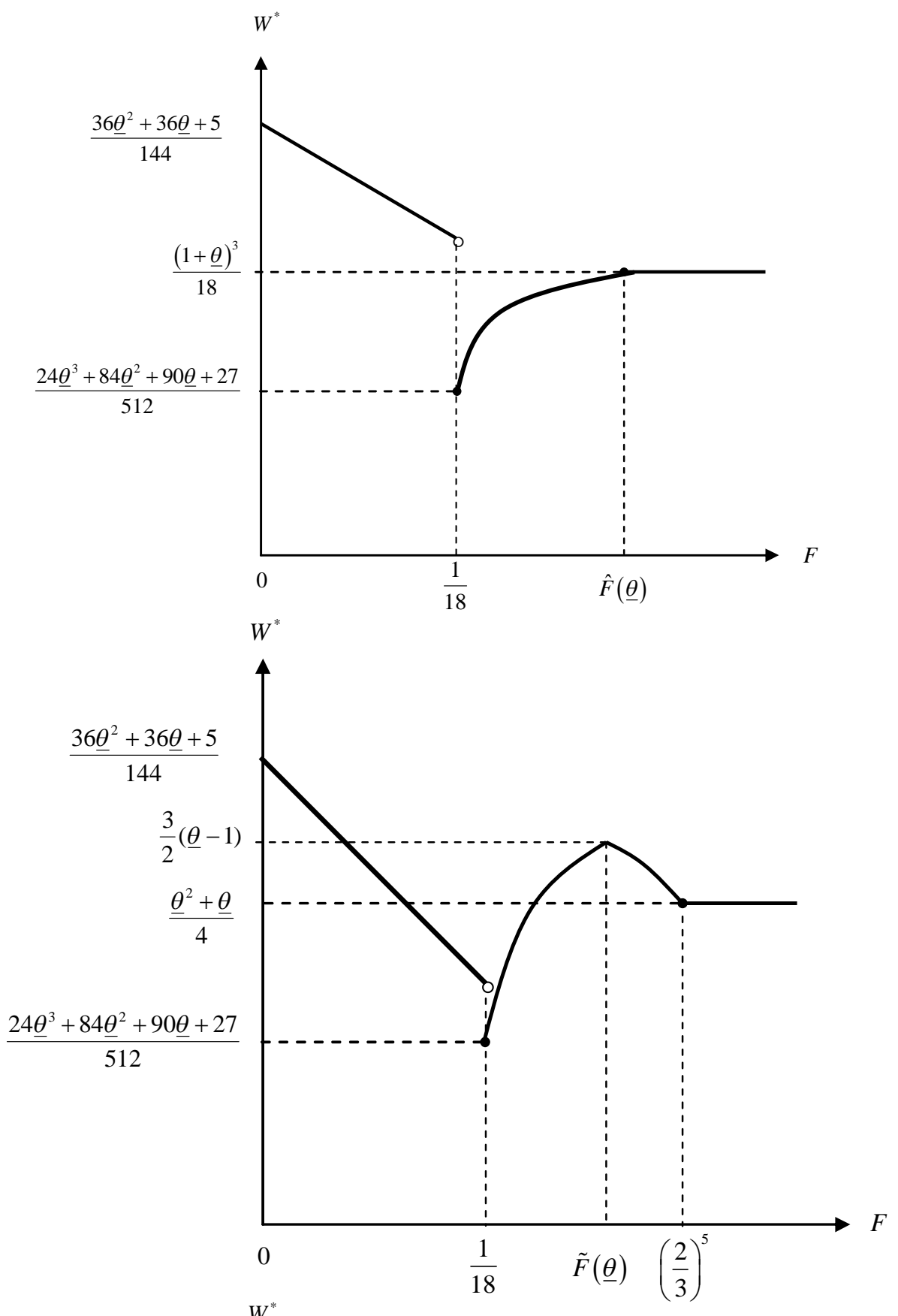

Figure 6-c.

Equilibrium Social Welfare

Case of $\underline{\theta} \geq 5 / 2$

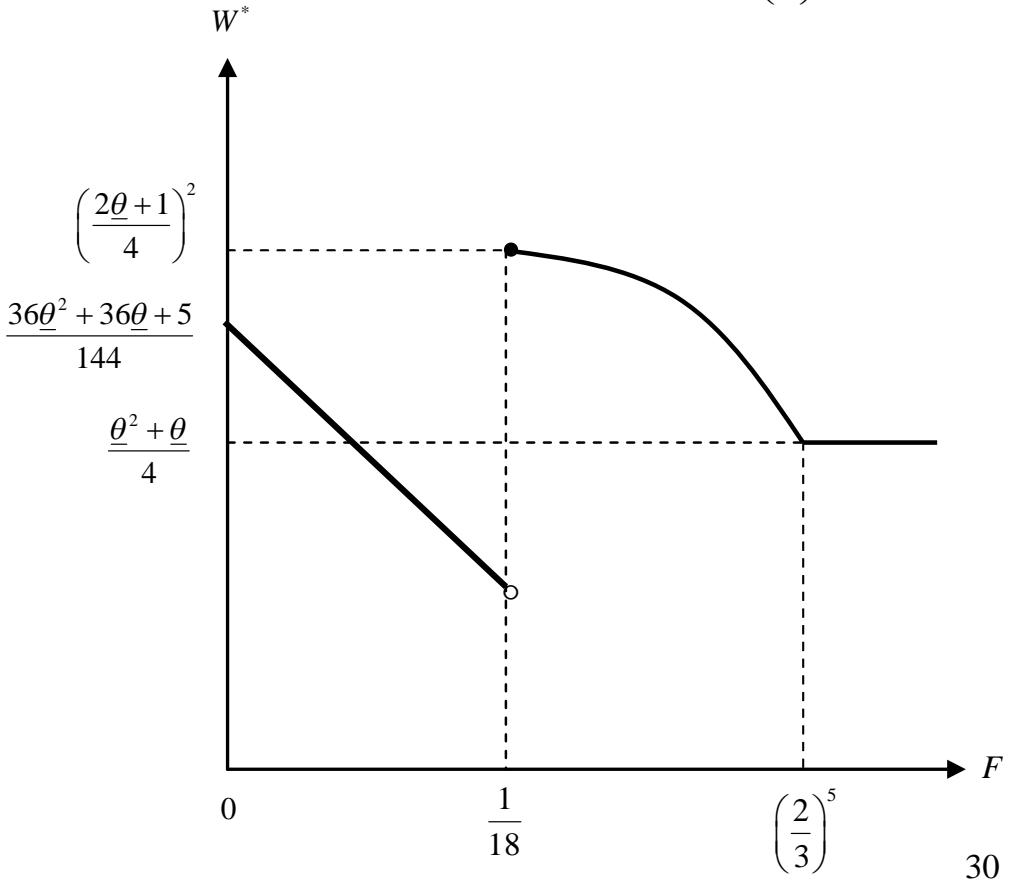

